\title{
Effect of Heat Treatment on Mechanical Properties of Al-1.5Cu-9.5Zn-3Mg Rapidly Solidified Alloy
}

\author{
EI Said Gouda ${ }^{1,2}$, Emad Makboul Ahmed ${ }^{1}$, Nabih Lotfi Tawfik ${ }^{1}$ \\ ${ }^{1}$ Metal Physics Lab., Solid State Physics Department, National Research Center, Dokki, Egypt; ${ }^{2}$ Physics Department, Faculty of \\ Science, Jazan University, Jazan, K.S.A. \\ Email: gouda.e173@yahoo.com
}

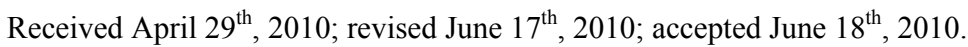

\begin{abstract}
Ribbons with the composition Al-1.5Cu-9.5Zn-3Mg were prepared by melt spinning technique. Microhardness and tensile strength were measured. The melt spun hardness and ultimate tensile strength values were as high as $291 \mathrm{HV}$ and $660 \mathrm{MN} / \mathrm{m}^{2}$, respectively. Hardness values are relaxed to lower values on prolonged thermal annealing to around $50 \%$. $X$-ray diffraction lines corresponding to $\mathrm{Cu}, \mathrm{Zn}$ and $\mathrm{Mg}$ were disappeared for the as melt spun ribbons, which indicates a complete solubility of these element in Al matrix. On prolonged thermal annealing these alloying elements were precipitated.
\end{abstract}

Keywords: Microhardness, Rapid Solidification, UTS, Tensile Strength

\section{Introduction}

The study of the material strength is an important subject because it is the first characteristic comes in mind when used in industrial applications specially that subjected to shock loading. Steel is a good example for the most strength materials, but its high density restricts its uses. Aluminum alloys are increasingly employed in many important manufacturing areas, such as the automobile industry, aeronautics and the military [1]. Currently, it offers the greatest potential for cost effective weight savings in automotive body structures and closures. With a density of only $33 \%$ of that of steel and a greater strength to weight ratio, there is the possibility for a weight savings of $40 \%$ to $50 \%$. Also, Mg alloys are very attractive materials for producing lightweight components for automobiles because they have densities that are $66 \%$ of $\mathrm{Al}$ alloys and $22 \%$ of steel. With their lower density and moderate strength, Al-Mg alloys are well suited for a number of applications, ranging from steering wheels and instrument panels to engine and transmission components. The mechanical properties of the Al-Mg plastically processed alloys depend on the content of magnesium in the alloy. With an increase of magnesium from 0.5 to $5 \%$ the properties increase; this rise is greater when magnesium increases from 3 to $6 \%$ [2]. There are many studies characterize the strength and mechanical properties of Al-based and Mg-based alloys with different elements [3-8]. The present paper aims to characterize hardness and tensile strength of the quaternary alloy $\mathrm{Al}-1.5 \mathrm{Cu}-9.5 \mathrm{Zn}-3 \mathrm{Mg}$ as an example for a high strength material.

\section{Experimental}

Al-1.5Cu-9.5Zn-3Mg alloy was prepared from 99.75 wt. $\%$ pure Al, 99.9 wt.\% pure $\mathrm{Cu}, \mathrm{Zn}$ and $\mathrm{Al}-10$ wt.\%Mg master alloy. The required quantities were weighted out and melted in electrical resistance furnace then thermally agitated to ensure the homogenization. The molten alloy was casted into graphite moulds to produce rods of 25 $\mathrm{mm}$ length and $4 \mathrm{~mm}$ diameter. A stream of the molten alloy at $850^{\circ} \mathrm{C}$ was ejected by argon gas at a gauge pressure of $1.5 \mathrm{~atm}$., from a silica tube with $0.5 \mu \mathrm{m}$ orifice diameter. The melt jet fell on a copper wheel of the melt spinning apparatus fixed at $2950 \mathrm{r} / \mathrm{m}$. The estimated cooling rate was about $10^{5} \mathrm{~K} / \mathrm{s}$. The resulting alloys are in ribbons form of about $50 \mu \mathrm{m}$ thickness and width 2 $\mathrm{mm}$. X-ray diffraction analyses was performed to identify the structure of the ribbons using a 1390 Philips X-ray Diffractometer with $\mathrm{Cu}$ radiation. The ribbons 
were tensile tested with a gauge length of $5 \mathrm{~cm}$ at strain rate of $1.66 \times 10^{-5} \mathrm{~s}^{-1}$, at room temperature. Measurements of hardness were done with the specimen placed against a glass slide with a load of $150 \mathrm{gm}$ and indentation time of $10 \mathrm{~s}$. Tests were done for the as melt-spun ribbons and for fully aged ribbons.

\section{Results and Discussion}

\subsection{X-Ray Diffraction}

The cooling rates of the melt spinning process exceed $10^{5}$ ${ }^{\circ} \mathrm{C} / \mathrm{s}$ was high enough to retain the high concentrations of the alloying elements in solid solution with the Al$1.5 \mathrm{Cu}-9.5 \mathrm{Zn}-3 \mathrm{Mg}$ alloy. This was confirmed by the presence of $\mathrm{Al}$ reflections only in the X-ray diffraction pattern of the as melt-spun ribbons as illustrated in Figure 1. For aged ribbon, the $\mathrm{Al}-\mathrm{Cu}$ compound and the alloying elements start to precipitate and crystal growth starts to be exist, so additional X-ray diffraction peaks were formed for the aged ribbons as illustrated in Figure 2. The additional diffraction lines were corresponding to pure $\mathrm{Mg}, \mathrm{Zn}$ and $\mathrm{Al}_{2} \mathrm{Cu}$ phases.

\subsection{Tensile Test}

Samples for the tensile test were chosen such that, a minimum variation in width and thickness has been obtained. The stander deviation in cross sectional area for each sample is $\pm 5 \%$. Samples with gauge length $5 \mathrm{~cm}$ were tested. Figure 3 shows the load-elongation curves for as melt-spun and annealed ribbons. Each curve can be divided into two regions. The first region is a linear and ends at strain ratio $\varepsilon / \varepsilon_{\mathrm{f}}$ about $80 \%$ and $30 \%$, for the as melt-spun and annealed samples, respectively, $\varepsilon_{\mathrm{f}}$ is the fracture strain. The second region is slightly curved due to yielding near the end of the test. Slope of the straight line in the first region represents Young's modulus of the as melt-spun sample. The ultimate tensile strength (UTS) for the as melt-spun sample was $660 \mathrm{MN} / \mathrm{m}^{2}$. This value decreased by annealing at $300^{\circ} \mathrm{C}$ for $5 \mathrm{~h}$ to $442 \mathrm{MN} / \mathrm{m}^{2}$. Also, toughness, which is expressed as the area under the load-elongation curve until fracture, was calculated. It was $3.98 \mathrm{MN} / \mathrm{m}^{2}$ for the as melt-spun samples and 3.39 $\mathrm{MN} / \mathrm{m}^{2}$ for the annealed sample.

\subsection{Microhardness}

Hardness of the as melt spun $\mathrm{Al}-1.5 \mathrm{Cu}-9.5 \mathrm{Zn}-3 \mathrm{Mg}$ alloy is $291 \mathrm{MN} / \mathrm{m}^{2}$ and decreases to $145 \mathrm{MN} / \mathrm{m}^{2}$ by thermal ageing at $220^{\circ} \mathrm{C}$ for $5 \mathrm{~h}$. This decrease takes place in two stages as illustrated in Figure 4. An initial fast stage follows by slow stage in which a slight decrease in hardness can be observed. The as-cast rod with the same composition gives the value of $141 \mathrm{MN} / \mathrm{m}^{2}$. By comparing the two values, it is noticed that, the as melt-spun ribbon has a much higher value than that of the as cast rods, which agreement with other results [9] for alloy rapidly solidified at different cooling rates. On thermal aging, the

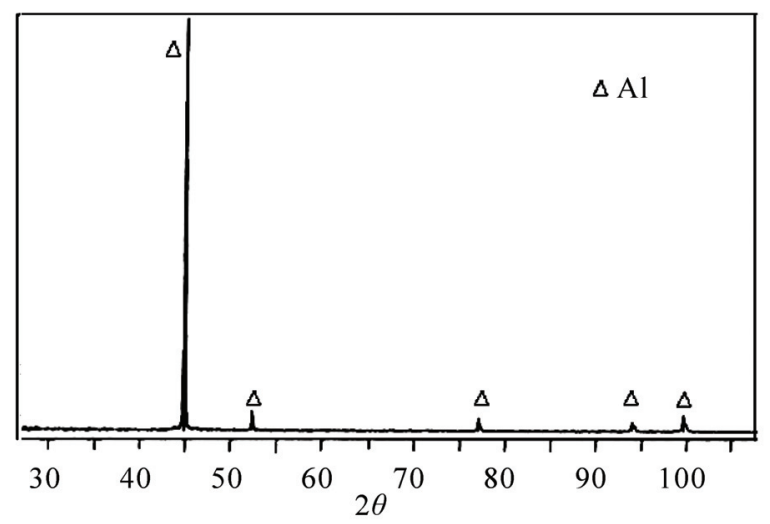

Figure 1. X-ray diffraction pattern of the Al-1.5Cu-9.5Zn3Mg melt spun ribbon.

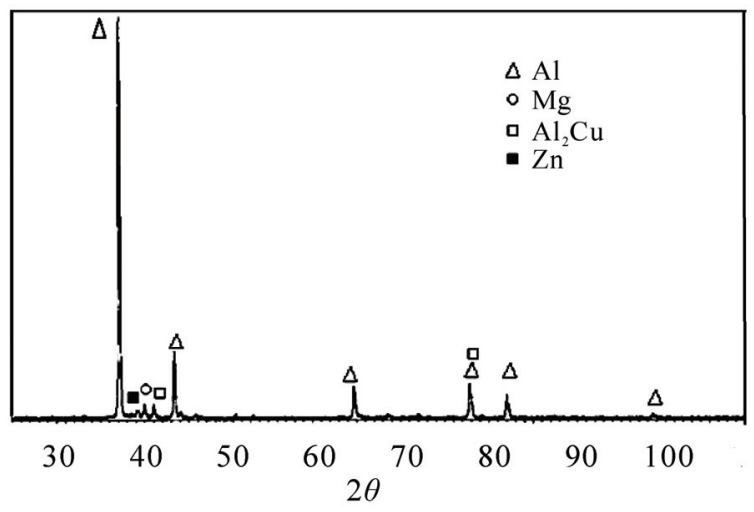

Figure 2. X-ray diffraction pattern of the Al-1.5Cu-9.5Zn$3 \mathrm{Mg}$ annealed ribbon.

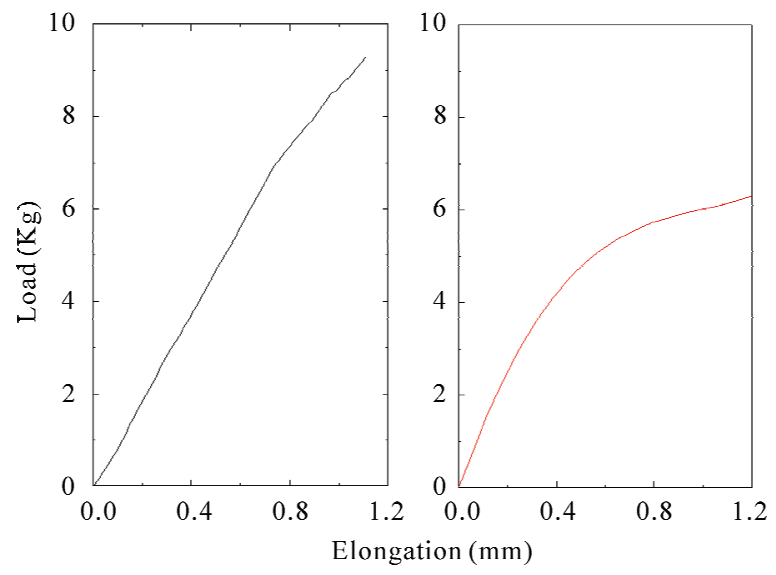

(a)

(b)

Figure 3. Load versus elongation for $\mathrm{Al}-1.5 \mathrm{Cu}-9.5 \mathrm{Zn}-3 \mathrm{Mg}$ melt spun ribbons (a) as melt spun and (b) aged for $5 \mathrm{~h}$ at $300^{\circ} \mathrm{C}$. 


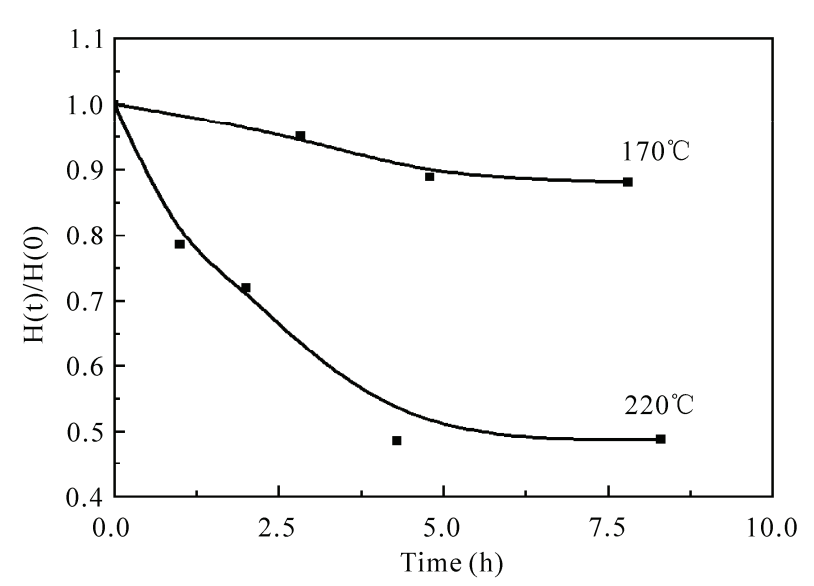

Figure 4. Variation of Vickers hardness ratio $\mathrm{H}(\mathrm{t}) / \mathrm{H}(\mathbf{0})$ at 170 and $220^{\circ} \mathrm{C}$ with aging time.

hardness decreases to reach limiting values of $50 \%$ of the as melt-spun values. It was observed that the hardness relaxation during isothermal ageing is much slower than that of resistivity relaxation at the same temperature. This behavior can be explained as that, hardness is closely related to size of precipitates. Also the electrical resistivity is sensitive to point defects which are usually the first properties to recover. On the other hand, the hardness depends more on line imperfection which may require higher temperatures for recovery. So, rapid solidification has a significant effect on increasing the hardness. The higher value of hardness for the as melt spun state can be attributed to the effect of the solute atoms upon the solvent lattice and the nature of the lattice forces operative owning to the interaction of different atomic spices.

\section{Conclusions}

The effects of rapid solidification and thermal heat treatments on the mechanical properties of quaternary Al1.5Cu-9.5Zn-3Mg melt spun alloy were studied. A maximum solid solubility value of $9.5 \mathrm{wt} . \% \mathrm{Zn}$ in $\alpha-\mathrm{Al}$ was obtained for the as melt-spun alloy, $3 \% \mathrm{Mg}$ and $1.5 \% \mathrm{Cu}$ were also obtained as solid solutions in Al-matrix. The existence of the alloying elements as solid solution in $\alpha$-Al significantly enhances microhardness, ultimate ten- sile strength U.T.S values. After aging the values relaxed to lower values as a result of the $\mathrm{Al}_{2} \mathrm{Cu}, \mathrm{Zn}$ and $\mathrm{Mg}$ precipitations. Hardness and U.T.S were as high as $291 \mathrm{HV}$ and $660 \mathrm{MN} / \mathrm{m}^{2}$, respectively.

\section{REFERENCES}

[1] S. J. Maddox, "Review of Fatigue Assessment Procedures for Welded Aluminum Structures," International Journal of Fatigue, Vol. 25, No. 12, 2003, pp. 1359-1378.

[2] J. R. Davis, "Aluminum and Aluminum Alloys," ASM International, Materials Park, OH, 1998.

[3] C. Zhou, X. Yang and G. Luan, "Investigation of Microstructures and Fatigue Properties of Friction Stir Welded Al-Mg Alloy," Journal of Materials Chemistry and Physics, Vol. 98, No. 2-3, 2006, pp. 285-290.

[4] B. Grushko E. Kowalska, B. Przepi and M. Surowiec, "An Investigation of the Al-Cu-Cr Phase Diagram: Phase Equilibria at $800-1000^{\circ} \mathrm{C}$," Journal of Alloys and Compounds, Vol. 417, No. 1-2, 2006, pp. 121-126.

[5] D. R. Fang, Z. F. Zhang, S. D. Wu, C. X. Huang, H. Zhang, N. Q. Zhao and J. Li, "Effect of Equal Channel Angular Pressing on Tensile Properties and Fracture Modes of Casting Al-Cu Alloys," Journal of Materials Science and Engineering A, Vol. 426, No. 1-2, 2006, pp. 305-313.

[6] B. B. Straumal, B. Baretzky, A. A. Mazilkin, F. Phillipp, O. A. Kogtenkova, M. N. Volkov and R. Z. Valiev, "Formation of Nanograined Structure and Decomposition of Supersaturated Solid Solution during High Pressure Torsion of Al-Zn and Al-Mg Alloys," Journal of Acta Materialia, Vol. 52, No. 15, 2004, pp. 4469-4478.

[7] A. Białobrzeski, and E. Czekaj, "An Attempt to Use Alloy Synthesis in Evaluating the Corrosion Behaviour of Aland Mg-Based Alloys," Journal of Materials Processing Technology, Vol. 175, No. 1-3, 2006, pp. 27-32.

[8] E. M. AbdelHady, N. L. Tawfik and E. S. Gouda, "Mechanical Properties of Some Al-Based Alloys with Heat Treatment," Journal of Heat Treatment and Surface Engineering, Vol. 8, No. 1-2, 2007, pp. 39-45.

[9] M. Kamal and E. S. Gouda, "Effect of Cooling Speed on Structure and Properties of Rapidly Solidified Pb-25wt.\% Sn Alloy," Journal of Radiation Effects and Defects in Solids, Vol. 162, No. 9, 2007, pp. 691-696. 